Case Reports
in Dermatology

\title{
Lymphatic Malformation Responsive to Sirolimus in Keratinocytic Epidermal Nevus Syndrome with KRAS Mutation: A Case and Brief Literature Discussion
}

\author{
Emily Sideris $^{a} \quad$ Er Tsing Vivian Tng ${ }^{a, b} \quad$ Paul Chee ${ }^{b, c}$ \\ aRoyal Australian College of General Practitioners, Newcastle, NSW, Australia; \\ ${ }^{b}$ Australasian College of Dermatologists, Rhodes, NSW, Australia; 'Department of \\ Dermatology, John Hunter Hospital, New Lambton Heights, NSW, Australia
}

\section{Keywords}

Genetic background · Epidermal nevus syndrome - Lymphatic malformation · Sirolimus

\section{Abstract}

We present a rare case of KRAS keratinocytic epidermal nevus syndrome with lymphatic malformation, responsive to treatment with sirolimus, an mTOR inhibitor. A brief review of the current literature regarding sirolimus use in vascular malformations, lymphatic malformations, regional overgrowth syndromes, and RASopathies is discussed.

\section{Introduction}

Vascular malformations (VM), lymphatic malformations (LM), and regional overgrowth syndromes are rare conditions that result predominantly from somatic gene mutations [1]. Mosaicism and the timing of the mutation during development cause phenotypical variance, resulting in variable disease progression and overlapping features that make diagnosis

\begin{tabular}{ll}
\hline & Emily Sideris \\
Department of Dermatology \\
John Hunter Hospital \\
New Lambton Heights, NSw 2305 (Australia) \\
emily.r.sideris@gmail.com
\end{tabular}




\section{Case Reports in Dermatology}

Case Rep Dermatol 2021;13:195-201

DOI: $10.1159 / 000515247$

(c) 2021 www.karger.com/cde

Sideris et al.: Lymphatic Malformation Responsive to Sirolimus in Keratinocytic Epidermal Nevus Syndrome with KRAS Mutation: A Case and Brief Literature Discussion

difficult $[2,3]$. Genetic research has shown the PI3K/AKT/mTOR pathway, especially the PIK3CA gene, and to a lesser degree the RAS/MAPK/MEK pathway play key roles in the regulation of angiogenesis, lymphangiogenesis, and cell growth [1, 3, 4]. Two overgrowth disorders associated with these pathways are congenital lipomatous overgrowth, VM, epidermal nevi, and spinal/skeletal anomalies syndrome (CLOVES) and epidermal nevus syndrome (ENS). Only four cases of keratinocytic ENS (KEN) involving a KRAS mutation, and one case of melorheostosis with linear epidermal nevus of KRAS mutation, have been reported [5-9].

Treatment of overgrowth syndromes, LM, and VM is often difficult as few effective medical treatments exist and surgically removed growths can recur [10-13]. Gene elucidation has allowed for more targeted therapies, including novel medications and the repurposing of preexisting medications such as sirolimus, an mTOR inhibitor, to be used, particularly where PIK3CA mutations are present [4,10-12]. However, little evidence currently exists as to the efficacy of sirolimus in non-malignant somatic RAS mutation conditions. We report such a case.

\section{Case}

A 21-year-old man with KEN presented with worsening lymphangiectasia of the right thigh. Diagnosed with KEN at age 4, he had aortic coarctation repair at the same age, bronchial artery haemorrhage and haemothorax with embolization repair at 16, hypertension, an anterior mediastinal mass, a hypoplastic right lung, bronchiectasis, and a congenital underdeveloped right kidney. Right-sided fibrous dysplasia with decreased mineralisation resulted in multiple prior fractures that healed poorly and necessitated lower leg amputation at age 13.

Clinical exam was significant for right-sided hypertrophy and multiple whorled, hyperpigmented and verrucous lesions in a Blaschkoid distribution to his torso and limbs, with right intra-knee amputation (Fig. 1). Persistent haemoserous ooze from the lymphangiectasia in the region of right hip, buttock, and thigh resulted in recurrent infections and severe anaemia requiring blood transfusion. Pain and swelling, leading to inability to use his prosthesis, necessitated the use of a wheelchair and significantly affected his quality of life.

The worsening lymphangiectasia with this history suggested a PIK3CA-related overgrowth spectrum (PROS) disorder diagnosis such as CLOVES. Samples were taken from his right thigh for genetic testing to confirm the genetic mutation. As frequent wound dressings, bleach baths, emollients, antibiotics, lymphoedema physiotherapy, iron infusion, and blood transfusions were having limited benefit, sirolimus as a novel treatment for PROS was initiated at a dose of $2 \mathrm{mg}$ daily. Within 1 month, improvement was noted with a reduction in haemoserous ooze, malodour, reduced frequency of dressings, and a noticeable clearance of some sections of pre-existing lymphangiectasia (Fig. 2). Few, small and non-weeping new areas were noted.

Genetic results received at this stage revealed a KRAS c35G>A, p.(Gly12Asp) mutation. Sirolimus was continued due to beneficial effect with the only adverse effect noted being abdominal pain manageable with simple analgesia that self-resolved within days of commencing treatment or dose change. Clinical improvement has been stable for 6 months with sirolimus dose titrated to a trough level of 5-9 $\mu \mathrm{g} / \mathrm{L}$. Current dosing is $2 \mathrm{mg}$ on weekdays and $1 \mathrm{mg}$ on weekends.

\section{Karger'=}




\section{Case Reports in Dermatology}

Case Rep Dermatol 2021;13:195-201

DOI: $10.1159 / 000515247$

(c) 2021 The Author(s). Published by S. Karger AG, Basel www.karger.com/cde

Sideris et al.: Lymphatic Malformation Responsive to Sirolimus in Keratinocytic Epidermal Nevus Syndrome with KRAS Mutation: A Case and Brief Literature Discussion

\section{Discussion}

Genetic research in recent years has begun to elucidate some of the genes involved in LM, VM, and overgrowth syndromes, enabling some diagnostic clarity. Considered a PROS disorder, a diagnosis of CLOVES is now more exclusive as it requires that a PIK3CA mutation be present in addition to a combination of the clinical features described in its name [13]. Conversely, ENS can involve different gene mutations despite it being considered a "mosaic RASopathy" due to a third of its cases reportedly involving a RAS mutation [5]. This differentiates ENS from the traditional RASopathies that have germline mutations rather than somatic mutations, such as neurofibromatosis-1 and Noonan syndrome [5]. For an ENS diagnosis a hamartomatous epidermal nevus overgrowth and a systemic anomaly must be present, such as ocular, skeletal, cardiovascular, or neural anomalies [2]. Whilst mutations in PIK3CA, FGFR3, HRAS, NRAS, and KRAS have all been reported in ENS, KRAS is predominantly found in sebaceous subtypes with only four cases of KRAS mutation KEN and one case of melorheostosis with KRAS linear epidermal nevus reported [2, 5-9].

At initial review of our patient, the combination of Blaschkoid epidermal nevus, LM with history of internal VM requiring embolization, hypoplastic right kidney, right sided skeletal asymmetry, and history of anterior mediastinal mass, possibly lipomatous, seemed to meet diagnostic criteria for CLOVES [13]. However, this was negated by the lack of PIK3CA gene mutation [13]. A rare diagnosis of KEN with KRAS mutation was instead established.

In initially making a clinical CLOVES diagnosis for our patient, a trial of oral sirolimus treatment was undertaken. An mTOR inhibitor approved as an immunosuppressant in transplant patients, discovery of the PI3K/AKT/mTOR pathway's role in LM, VM, and associated overgrowth syndromes led to sirolimus being used as a palliative treatment for a severe vascular anomaly in a child, with resultant decreased anomaly size [4]. Numerous studies but few trials have been reported since, and only one report of an NRAS mutation VM showing a response to sirolimus exists $[4,14]$. Recent reports note sirolimus is generally efficacious and safe in treating various VM, LM, and some overgrowth conditions, particularly where PIK3CA mutations are present, including in PROS [10-12].

With KRAS mutation found, the effect of sirolimus on our patient is not completely understood. It may be explained by the interconnection between the RAS/MAPK/MEK and $\mathrm{PIK} / \mathrm{AKT} / \mathrm{mTOR}$ pathways that has been described in recent years, with RAS influencing both PI3K/AKT and its downstream substrates [3,15]. Vascular endothelial growth factors (VEGF) that regulate angiogenesis and lymphangiogenesis are stimulated by the two paths activating mTOR signalling, with mutations producing enhanced signalling that results in overstimulation and growth $[3,11,14,15]$. Mutations of KRAS in particular have been associated with lymphangiectasia in developmental RASopathies such as Noonan syndrome [15]. Sirolimus has therefore been used in these RASopathies, with beneficial effect reported in a few case reports and series, with ongoing trials into their use occurring [14]. However, this is the first reported case of beneficial sirolimus effect in a KRAS mosaic RASopathy.

Adverse effects of sirolimus reported in the literature include hypercholesterolaemia, deranged liver function, thrombocytopenia, leukopenia, stomatitis and mucositis, abdominal pain, nausea, and infections including respiratory tract, sinusitis, cellulitis, and bacteraemia, but sirolimus is reported overall to be well tolerated without significant adverse effects [1012]. This is consistent with our patient's report of tolerable and brief abdominal pain. With the potential blood dyscrasias and the need to titrate the dose to a trough of 5-9 $\mu \mathrm{g} / \mathrm{L}$, regular review and pathology are needed, including full blood count, biochemistry, liver function tests,

\section{Karger'=}




\section{Case Reports in Dermatology}

\begin{tabular}{l|l}
\hline DOI: $10.1159 / 000515247$ & (c) 2021 The Author(s). Published by S. Karger AG, Basel
\end{tabular} www.karger.com/cde

Sideris et al: Lymphatic Malformation Responsive to Sirolimus in Keratinocytic Epidermal Nevus Syndrome with KRAS Mutation: A Case and Brief Literature Discussion

and lipids. The protocol we followed involved monthly blood tests for the first 3 months, with reduced frequency from then if stable. Sirolimus trough levels were taken 10-12 hours after dosing at days 5,12 , and 26, with dose titrated accordingly. Clinical review was conducted every 2-3 months with phone consults between visits as needed. Duration of treatment needed in these conditions is not clear from the literature and varies for each patient [4].

With current research into more targeted agents, it may be possible to offer our patient a novel medication in the future. For now, our patient is receiving definite benefit from sirolimus with minimal and transient adverse effects. Whilst sirolimus is not a direct treatment for KRAS mutation somatic syndromes, our case adds to the limited evidence that it can be a beneficial and well-tolerated treatment in such cases.

\section{Statement of Ethics}

The research was conducted ethically in accordance with the World Medical Association Declaration of Helsinki. Written informed consent to publish the case and images has been obtained from the patient.

\section{Conflict of Interest Statement}

There are no known conflicts of interest to disclose.

\section{Funding Sources}

None.

\section{Author Contributions}

Corresponding author Emily Sideris drafted the manuscript and performed the majority of the research, with Er Tsing Vivian Tng contributing to research. All three authors substantially contributed to the conceptual design of the manuscript and its revision and approved the final version for submission.

\section{References}

1 Ten Broek RW, Eijkelenboom A, van der Vleuten CJ, Kamping EJ, Kets M, Verhoeven BH, et al. Comprehensive molecular and clinicopathological analysis of vascular malformations: A study of 319 cases. Genes Chromosomes Cancer. 2019 Aug;58(8):541-50.

2 Flores-Sarnat L, Sarnat HB. Chapter 2 - Phenotype/genotype correlations in epidermal nevus syndrome as a neurocristopathy, Editor(s): Islam MP, Roach ES, Handbook of Clinical Neurology, Elsevier, 2015;132:9-25. doi.org/10.1016/B978-0-444-62702-5.00002-0.

3 Ozeki M, Fukao T. Generalized Lymphatic Anomaly and Gorham-Stout Disease: Overview and Recent Insights. Adv Wound Care (New Rochelle). 2019 Jun;8(6):230-45.

4 Adams DM, Ricci KW. Vascular Anomalies: Diagnosis of Complicated Anomalies and New Medical Treatment Options. Hematol Oncol Clin North Am. 2019 Jun;33(3):455-70.

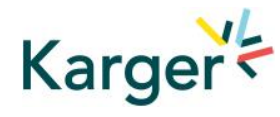




\section{Case Reports in Dermatology}

\begin{tabular}{l|l}
\hline Case Rep Dermatol 2021;13:195-201 \\
\hline DOI: 10.1159/000515247 & $\begin{array}{l}\text { @ 2021 The Author(s). Published by S. Karger AG, Basel } \\
\text { www.karger.com/cde }\end{array}$ \\
\hline
\end{tabular}

Sideris et al.: Lymphatic Malformation Responsive to Sirolimus in Keratinocytic Epidermal Nevus Syndrome with KRAS Mutation: A Case and Brief Literature Discussion

5 Hafner C, Toll A, Gantner S, Mauerer A, Lurkin I, Acquadro F, et al. Keratinocytic epidermal nevi are associated with mosaic RAS mutations. J Med Genet. 2012 Apr;49(4):249-53.

6 Bourdeaut F, Hérault A, Gentien D, Pierron G, Ballet S, Reynaud S, et al. Mosaicism for oncogenic G12D KRAS mutation associated with epidermal nevus, polycystic kidneys and rhabdomyosarcoma. J Med Genet. 2010 Dec;47(12):859-62.

7 Whyte MP, Griffith M, Trani L, Mumm S, Gottesman GS, McAlister WH, et al. Melorheostosis: exome sequencing of an associated dermatosis implicates postzygotic mosaicism of mutated KRAS. Bone. 2017 Aug;101:145-55.

8 Farschtschi S, Mautner VF, Hollants S, Hagel C, Spaepen M, Schulte C, et al. Keratinocytic epidermal nevus syndrome with Schwann cell proliferation, lipomatous tumour and mosaic KRAS mutation. BMC Med Genet. 2015 Feb;16(6):6.

9 Igawa S, Honma M, Minami-Hori M, Tsuchida E, Iizuka H, Ishida-Yamamoto A. Novel postzygotic KRAS mutation in a Japanese case of epidermal nevus syndrome presenting with two distinct clinical features, keratinocytic epidermal nevi and sebaceous nevi. J Dermatol. 2016 Jan;43(1):103-4.

10 Wiegand S, Wichmann G, Dietz A. Treatment of Lymphatic Malformations with the mTOR Inhibitor Sirolimus: A Systematic Review. Lymphat Res Biol. 2018 Aug;16(4):330-9.

11 Sandbank S, Molho-Pessach V, Farkas A, Barzilai A, Greenberger S. Oral and Topical Sirolimus for Vascular Anomalies: A Multicentre Study and Review. Acta Derm Venereol. 2019 Oct;99(11):990-6.

12 Parker VER, Parker VE, Keppler-Noreuil KM, Faivre L, Luu M, Oden NL, De Silva L, et al.; PROMISE Working Group. Safety and efficacy of low-dose sirolimus in the PIK3CA-related overgrowth spectrum. Genet Med. 2019 May;21(5):1189-98.

13 Martinez-Lopez A, Blasco-Morente G, Perez-Lopez I, Herrera-Garcia JD, Luque-Valenzuela M, Sanchez-Cano D, et al. CLOVES syndrome: review of a PIK3CA-related overgrowth spectrum (PROS). Clin Genet. 2017 Jan;91(1):14-21.

14 Salido-Vallejo R, Garnacho-Saucedo G, Vélez A. Elucidation of the mTOR Pathway and Therapeutic Applications in Dermatology [English Edition]. Actas Dermosifiliogr. 2016 Jun;107(5):379-90.

15 Brouillard P, Boon L, Vikkula M. Genetics of lymphatic anomalies. J Clin Invest. 2014 Mar;124(3):898-904. 


\section{Case Reports in Dermatology}

\begin{tabular}{l|l}
\hline Case Rep Dermatol 2021;13:195-201 \\
\hline DOI: 10.1159/000515247 & $\begin{array}{l}\text { @ 2021 The Author(s). Published by S. Karger AG, Basel } \\
\text { www.karger.com/cde }\end{array}$ \\
\hline
\end{tabular}

Sideris et al: Lymphatic Malformation Responsive to Sirolimus in Keratinocytic Epidermal Nevus Syndrome with KRAS Mutation: A Case and Brief Literature Discussion

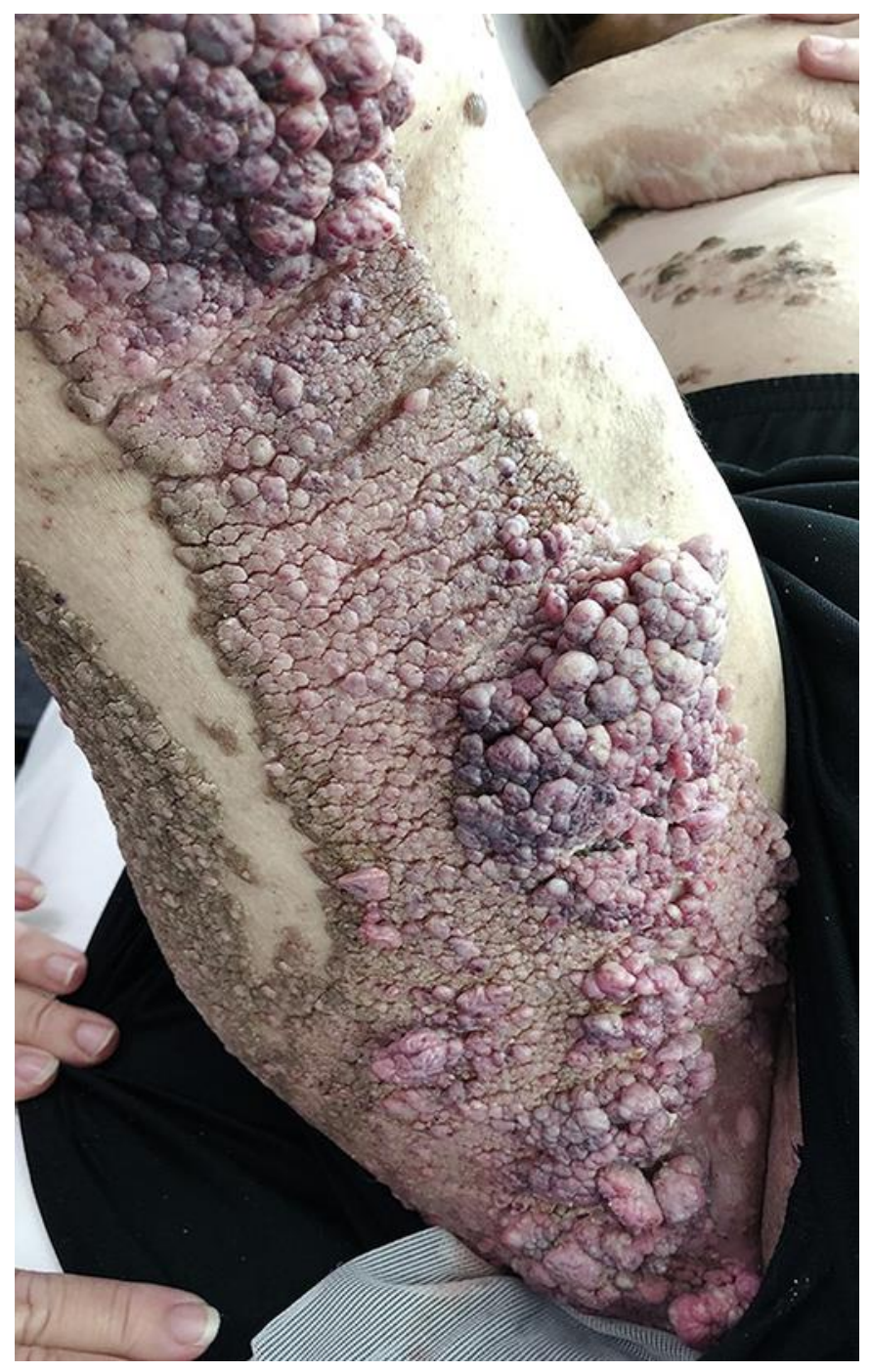

Fig. 1. Right thigh pre-sirolimus initiation. 


\section{Case Reports in Dermatology}

Case Rep Dermatol 2021;13:195-201

DOI: $10.1159 / 000515247$

(c) www.karger.com/cde

Sideris et al:: Lymphatic Malformation Responsive to Sirolimus in Keratinocytic Epidermal Nevus Syndrome with KRAS Mutation: A Case and Brief Literature Discussion

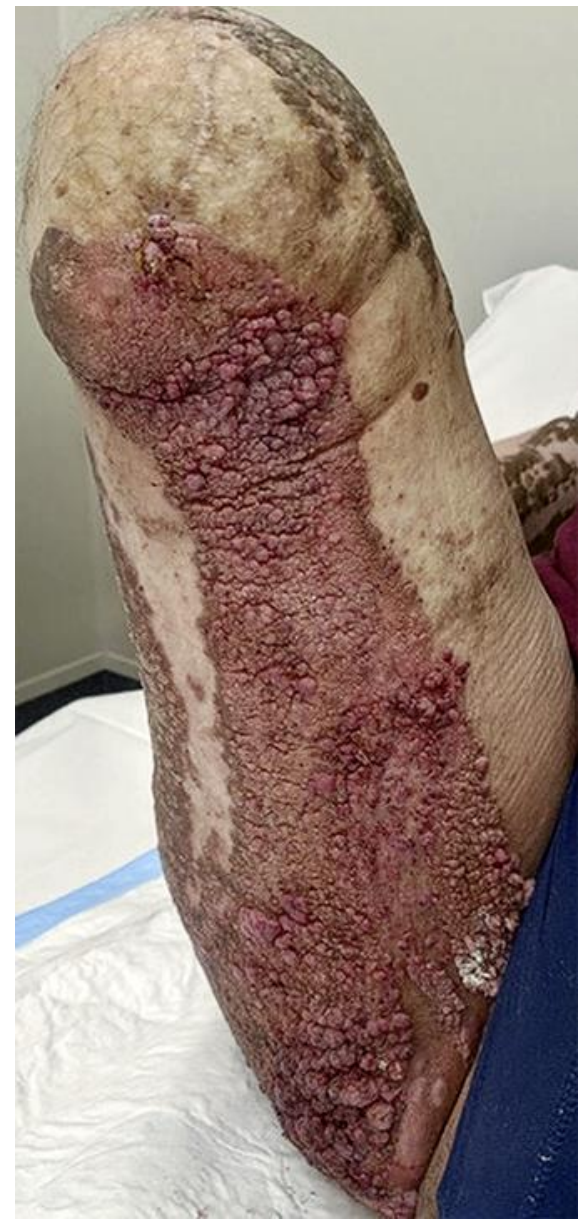

Fig. 2. Right thigh 10 weeks post sirolimus initiation. 